\title{
Toxicity and bioaccumulation of ethofumesate enantiomers in earthworm Eisenia fetida
}

\author{
Peng Xu, Yinghuan Wang, Yanfeng Zhang, Jianzhong Li, Huili Wang* \\ Research Center for Eco-Environmental Sciences, Chinese Academy of Sciences, Shuangqing RD 18, Beijing 100085, China
}

\section{H I G H L I G H T S}

- The acute toxicity of ethofumesate enantiomers to earthworm was enantioselective.

- The bioavailability of ethofumesate was determined using accumulation kinetics.

- The elimination of ethofumesate in earthworm was fast with a half life of $1.8 \mathrm{~d}$.

- A linear relationship between Log BSAFs and Log $K_{\text {ow }}$ was observed.

- The elimination rate of some pesticides was independent of the $K_{\mathrm{ow}}$.

\section{A R T I C L E I N F O}

\section{Article history:}

Received 31 December 2013

Received in revised form 27 March 2014

Accepted 28 March 2014

Available online 8 May 2014

Handling Editor: Tamara S. Galloway

\section{Keywords:}

Earthworm

Ethofumesate

Toxicity

Bioaccumulation

Elimination

\begin{abstract}
A B S T R A C T
Earthworms represent an important food source for many vertebrates and as a result, predators may encounter toxic effects via the food chain from consumption of contaminated worms. Therefore, including an assessment of xenobiotic to worms in risk assessment procedures is advisable. Here we studied the acute toxicity, bioaccumulation and elimination of ethofumesate enantiomers in earthworm, Eisenia fet$i d a$, in a soil. A slight difference in toxicity to earthworm between two enantiomers was found, and the calculated $\mathrm{LC}_{50}$ values for (+)-, rac- and (-)-ethofumesate were $4.51,5.93$ and $7.98 \mu \mathrm{g} / \mathrm{cm}^{2}$, respectively, indicating that the acute toxicity of ethofumesate enantiomers was enantioselective. Earthworm can uptake ethofumesate but the bioaccumulation curve did not reach the steady state. In the elimination experiment, the concentrations of ethofumesate in earthworm declined following a first-order decay model with a short half life of $1.8 \mathrm{~d}$. The bioaccumulation and elimination of ethofumesate in earthworm were both nonenantioselective. In combination with other studies, a linear relationship between Log BSAFs and Log $K_{\text {ow }}$ was observed, and the Log BSAFs increased with increasing Log $K_{\text {ow }}$. But the elimination rate did not show any correlation with the $K_{\text {ow }}$ value.
\end{abstract}

(c) 2014 Elsevier Ltd. All rights reserved.

\section{Introduction}

The increasing dependence on pesticides to enhance crop yields and food quality and the frequent presence of residues of these compounds in soil and water have become major environmental issues of concern (Matthews, 2006). This concern is due to the hazards to human health associated with the potential presence of these compounds in soil, drinking water or the food chain (Sáenz de CabezónIrigaray et al., 2009). Earthworms are the predominant biomass in most temperate terrestrial ecosystems, and they are in near constant contact with the soil, perform vital ecological functions, represent a significant fraction of the diet of some terrestrial vertebrates, and can serve as surrogates for higher order organisms

\footnotetext{
* Corresponding author. Tel.: +86 1062849385; fax: +86 1062946988.

E-mail address: winxp@cau.edu.cn (H. Wang).
}

(Snyder et al., 2011). Earthworms process large amounts of soil through their feeding and burrowing activities (Lavelle et al., 1997; Shan et al., 2010). Consequently, earthworms can accumulate many organic and inorganic soil pollutants, and they are therefore ideal testing organisms for the bioaccumulation of pollutants in soil (Jager et al., 2003; Kinney et al., 2008). Many studies have reported the bioaccumulation of various contaminants in earthworms, including heavy metals and organic pollutants (Kizilkaya, 2004; Jager et al., 2005; Shang et al., 2013). Regardless of all these data, the bioaccumulation of ethofumesate in earthworm has not been reported.

Ethofumesate (Fig. S1) is a benzofuranyl alkanesulfonate herbicide and used in pre- and post-emergence control of grasses and broad-leaved weeds in sugar beet and other crops, and in turf, ryegrass and other pasture grasses (Wilson, 1999; Kawahigashi et al., 2002; Xu et al., 2012). Ethofumesate is absorbed by the emerging 
shoots (grass coleoptile and broadleaf hypocotyl) and roots with translocation to the foliage (Kucharski and Sadowski, 2009), and the mode of action is related to inhibition of mitosis plus reduced photosynthesis and respiration (US Environmental Protection Agency, 2005).

Ethofumesate, [( \pm )-2-ethoxy-2,3-dihydro-3,3-dimethylbenzofu ran-5-ylmethansulfonate], is C-chiral due to the presence of an asymmetrically substituted C-atom in the furan moiety with a pair of enantiomers. In theory, enantiomers have identical physical and chemical properties and abiotic degradation rates (Garrison et al., 1996), whereas their individual toxicity, biological activity, and microbial degradation rates have been shown to differ (Overmyer et al., 2007; Diao et al., 2010; Liu et al., 2012; Sun et al., 2012). Several studies have reported that ethofumesate enantiomers showed an enantioselectivity in biochemical processes. Wang et al. (2005) found the degradation of ethofumesate in turfgrass was enantioselective with a preferencial degradation of $(-)$-ethofumesate. Xu et al. (2012) reported the metabolic of ethofumesate in rat hepatocytes was enantioselective, whereas it was not in chicken hepatocytes. They also found toxicity of ethofumesate enantiomers to rat and chicken hepatocytes were both enantioselective, and the stereoselective cytotoxicity of the two enantiomers was opposite in rat and chicken hepatocytes. Thus, when agrochemicals have chiral structures, efforts should be made to define the human and environmental toxicity of each enantiopure isomer. Information on the stereoselective toxicity effects and bioaccumulation of chiral pesticides will help improve our understanding of the pesticide's safety to humans, animals and the environment.

At present toxicity and bioaccumulation tests are valuable tools for assessing bioavailability (Katayama et al., 2010), and because earthworms have gained acceptance for use in tests to assess the effects of chemicals on soil organisms, it is necessary to evaluate the toxicity and bioaccumulation of pesticides to earthworms. However, except the bioaccumulation, potential toxicity impacts of ethofumesate enantiomers to earthworms are unknown. Several earthworm protocols have been developed to assess the effects of chemicals on earthworms (Eisenia fetida) among which the most well-known is the OECD guideline 207 (OECD, 1984). According to this guideline, the paper contact toxicity test is described as an initial screen to indicate the chemicals likely to be toxic to earthworms in soil. In addition, a previous study reported that for chemicals with a $\log K_{\text {ow }}$ below 5 , the skin is probably the most important route, while the gut becomes an important route for chemicals above approximately 5 and dominates above 6 (Jager et al., 2003). Because the Log $K_{\text {ow }}$ of ethofumesate was 2.7, skin exposure is a relevant uptake route, which can be assessed by the paper contact test. In this study, we investigated the acute toxicity assay of ethofumesate enantiomers to earthworm using paper contact test under laboratory condition. We also developed a suitable analytical method to detect the amounts of two enantiomers of ethofumesate in earthworms and soil samples and evaluate the bioaccumulation and elimination of the two enantiomers in earthworm.

\section{Materials and methods}

\subsection{Chemicals and reagents}

Racemic ethofumesate standard ( $\geqslant 98.5 \%$ purity) was provided by Institute for the Control of Agrochemicals, Ministry of Agriculture (ICAMA, Beijing, China). The solubility in water and the $\log K_{\text {ow }}$ of ethofumesate is $50 \mathrm{mg} / \mathrm{L}$ and 2.7 , respectively. Water was purified by a Milli-Q system. Isopropanol (HPLC grade) and $n$-hexane (HPLC grade) were obtained from Fisher Scientific (Fair Lawn, NJ, USA). Ethyl acetate, acetone and acetonitrile were of analytical grade and purchased from Beijing Chemical Reagent Co. Ltd. (Beijing, China).

\subsection{Earthworms and soil collection}

Mature redworms (E. fetida) purchased from northern suburbs farm, Beijing, were maintained in a wooden breeding box $\left(50 \times 50 \times 20 \mathrm{~cm}^{3}\right)$ containing a mixture of soil and cattle manure. The worms weighting between 200 and $300 \mathrm{mg}$ were active when being introduced in the experiment.

The site to collect soil is a grassland area $20 \mathrm{~km}$ northwest of Beijing, China, which have not received any pesticide applications for 10 years at least. After removing the grasses and stones, the top soil $(0-10 \mathrm{~cm})$ was collected. The soils were sieved $(2 \mathrm{~mm})$ and airdried at room temperature and stored in dark area until a few days before using. Physicochemical properties of the soil were as follows: organic matter $(\mathrm{OM}), 2.13 \pm 0.12 \%$; clay $(<2 \mu \mathrm{m}), 4.7 \pm 0.1 \%$; sand $(2000-20 \mu \mathrm{m}), 54.3 \pm 1.4 \%$; silt $(<20-2 \mu \mathrm{m}), 40.1 \pm 1.2 \%$; water holding capacity, $44 \%$ and $\mathrm{pH}, 7.6 \pm 0.2$.

\subsection{Experimental procedures}

\subsubsection{Acute toxicity test}

To obtain the individual enantiomers of ethofumesate for acute toxicity assay, the resolved enantiomers were prepared automatically on an Agilent 1200 HPLC system with a preparatory chiral column $(250 \mathrm{~mm} \times 10 \mathrm{~mm}$ I.D., provided by the Department of Applied Chemistry, China Agricultural University, Beijing) based on cellulose tri-(3,5-dimethylphenyl-carbamate) (CDMPC) chiral stationary phase (CSP). The elution orders of right and left-rotation enantiomers of ethofumesate were measured by CHIRALYSER-MP optical rotation detector produced by IBZ MESSTECHNIK Company (Germany). The optical signals were received and processed by a N2000 SP1 chromatographic workstation obtained from Zhejiang University Zhida information Engineering Co., Ltd. (Hangzhou, China). The result showed the first eluted enantiomer was dextro isomer defined as (+)-enantiomer, and that the second eluted enantiomer was laevo isomer defined as (-)-enantiomer using $n$ hexane/isopropanol (90:10 by volume) as the mobile phase (Fig. 1). The purity for both enantiomers was $>99 \%$, and the concentrations for the resolved enantiomers were determined by comparison with racemic solution of known concentration. Stock solution of $4000 \mathrm{mg} / \mathrm{L}$ were prepared in acetone for (+)-, rac- and (-)-ethofumesate, respectively, and stocked at $4{ }^{\circ} \mathrm{C}$.

The acute toxicity test was conducted according to the OECD guideline 207 using a paper contact toxicity assay. Briefly, after the depuration period of $24 \mathrm{~h}$ on wet filter paper under dark conditions to evacuate the gut content of earthworms, earthworms were rinsed in tap water and dried by absorbent paper cautiously. The filter paper $\left(5.5 \times 11.5 \mathrm{~cm}^{2}\right)$ was placed in flat-bottomed glass vial ( $3.6 \mathrm{~cm}$ in diameter, $8 \mathrm{~cm}$ in length). One milliliter of test solutions was pipetted and added to the filter paper in glass vial. The test solutions with the highest concentrations were prepared by spiking the stock solution to the acetone. Subsequent dilution was made from the highest concentration to derive the lower concentration solutions. The nominal concentrations were $1.58,3.16$, $6.32,12.65,15.81,18.97 \mu \mathrm{g} / \mathrm{cm}^{2}$ for (+)-ethofumesate, $1.58,3.16$, $6.32,7.91,12.65,15.81 \mu \mathrm{g} / \mathrm{cm}^{2}$ for rac-ethofumesate, and $3.16,6.32,12.65,15.81,18.97,23.72 \mu \mathrm{g} / \mathrm{cm}^{2}$ for (-)-ethofumesate. After drying of the solvent under a stream of compressed air, one milliliter of deionized water was added to each vial. Controls were also run in parallel with the carrier solvent alone. Ten replicates for each treatment and each vial containing one worm were done. Each vial was sealed with plastic film with several ventilation holes. After that all the vials were placed in a room at $20 \pm 2{ }^{\circ} \mathrm{C}$, and mortality of earthworms was observed after incubation for 


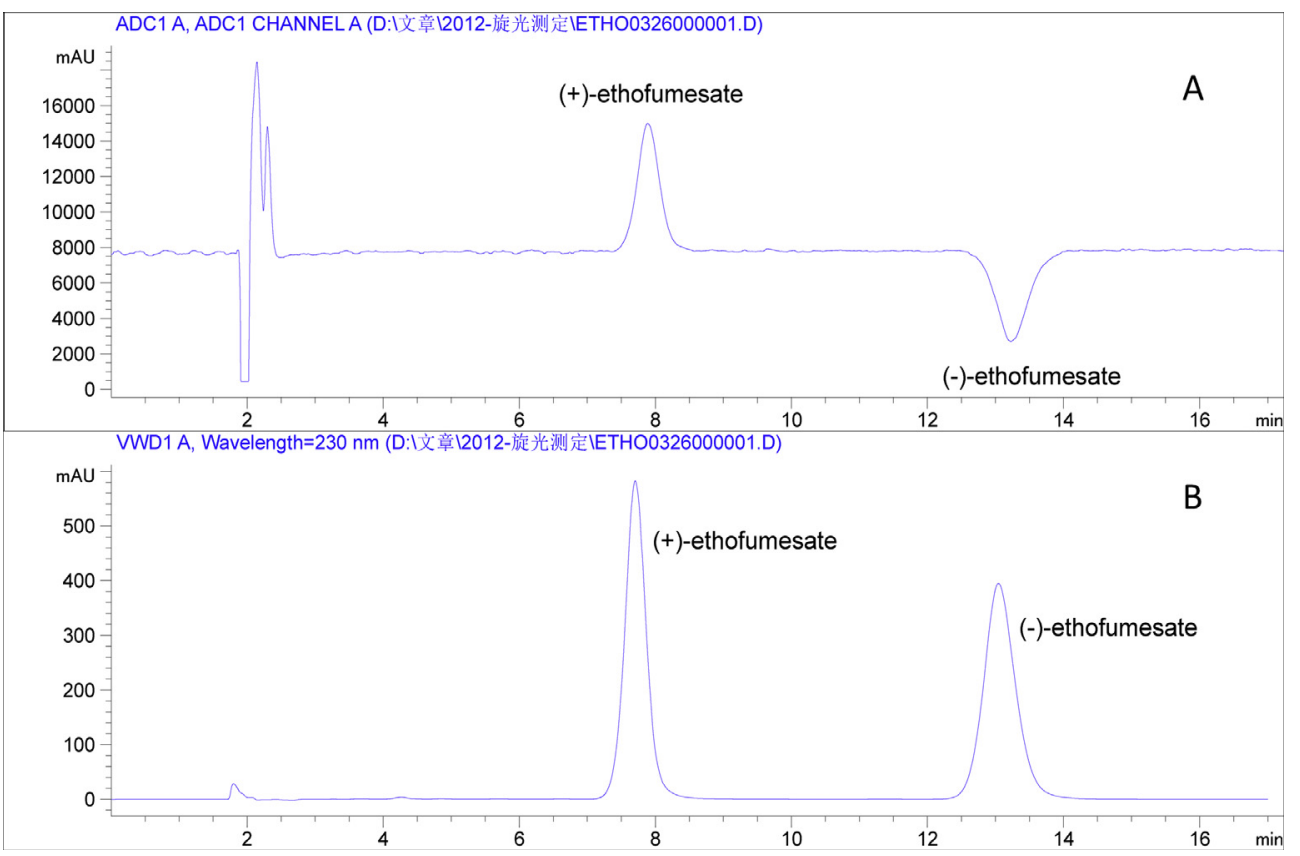

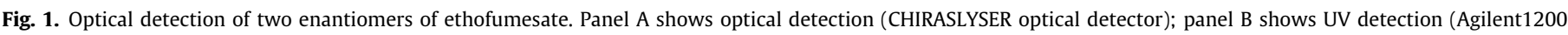
HPLC with UV detector) [flow rate $0.5 \mathrm{~mL} / \mathrm{min}, \mathrm{UV}=230 \mathrm{~nm}, n$-hexane/isopropanol = 90/10].

$48 \mathrm{~h}$. The $\mathrm{LC}_{50}$ values were determined from the survival data using a probit equation with SPSS 16.0.

\subsubsection{Bioaccumulation and elimination test}

In order to disperse the test substances ethofumesate homogeneously within the $250 \mathrm{~g}$ dry weight soil, we did the dilution spike procedure in steps (Jager et al., 2003). First, the chemical (10.0 mg) was dissolved in $10 \mathrm{~mL}$ of acetone, and then the acetone solution was slowly added to dry soil ( $50 \mathrm{~g}$ ) while mixing continued for about $5 \mathrm{~min}$. The spiked soil was left in a fume cupboard over-night and then all of the acetone evaporated off. Next, the contaminated dry soil $\left(50 \mathrm{~g}_{\mathrm{dwt}}\right)$ was mixed thoroughly with $200 \mathrm{~g}_{\mathrm{dwt}}$ of uncontaminated medium. The contaminated soil $\left(250 \mathrm{~g}_{\mathrm{dwt}}\right)$ was transferred to a $500 \mathrm{~mL}$ glass jar. The final concentration of ethofumesate in soil was $40 \mathrm{mg} / \mathrm{kg}_{\text {dwt }}$. Ninety gram tap water was added to each jar to restore the $80 \%$ of water holding capacity. Before the worms were introduced, they were allowed to live in that kind of uncontaminated soil for one week to acclimate. After evacuating their gut contents on moist filter paper for $3 \mathrm{~h}$ at $20^{\circ} \mathrm{C}, 10 \mathrm{~g}_{w w t}$ earthworms were exposure to ethofumesate in each jar containing $340 \mathrm{~g}_{\mathrm{wwt}}$ contaminated soil. The jars containing contaminated soil and worms were weighed. The loss of water by evaporation was compensated by addition of tap water every two days. All the jars were placed in dark in environmental chamber controllable to $20 \pm 2{ }^{\circ} \mathrm{C}$.

For the bioaccumulation experiment, the duration of this phase was $40 \mathrm{~d}$, and samplings were performed at days $0.5,1,3,5,10,14$, 20,30 and 40 . Three replicates were used for each sampling time. At each sampling time, surviving earthworms were collected from the test soil, washed in tap water, and placed onto moist filter paper for approximately $3 \mathrm{~h}$ to void their gut contents, following the recommendation of Jager et al. (2003). Water on the surface of the worms was dried by absorbent paper gently, and then the worms were weighed and frozen at $-20{ }^{\circ} \mathrm{C}$ (in $50 \mathrm{~mL}$ of polypropylene tubes). Soil samples ( $\left.6.8 \mathrm{~g}_{\mathrm{wwt}}\right)$ sampled from each jar were also stored at $-20^{\circ} \mathrm{C}$.

To study the elimination kinetics of ethofumesate in the earthworm bodies, $10 \mathrm{~g}$ earthworms were exposed to ethofumesate in
$340 \mathrm{~g}_{\mathrm{wwt}}$ soil as in the uptake experiment described above. After $14 \mathrm{~d}$ of exposure, the earthworms were transferred to a new flask containing $340 \mathrm{~g}_{\text {wwt }}$ fresh soil lacking ethofumesate. During the elimination period, worms were collected after $0.25,0.5,1,2$ and $4 \mathrm{~d}$. After $3 \mathrm{~h}$ of depuration and drying of the external water, the worms were stored at $-20^{\circ} \mathrm{C}$. All experiments were performed in triplicate.

Earthworms were not fed for the first $14 \mathrm{~d}$ of the bioaccumulation phase or during the elimination phase. Earthworms were fed approximately $5 \mathrm{~mL}$ cooked oatmeal (1:3 oatmeal:deionized water, $\mathrm{v}: \mathrm{v})$, on days 14 and 30 of the bioaccumulation phase.

\subsection{Sample extraction and chemical analysis}

\subsubsection{Sample extraction}

For the sample pretreatment of soil, samples were first thawed at room temperature. The $5 \mathrm{~g}$ samples (dry weight basis) and were then removed and placed into $50 \mathrm{~mL}$ polypropylene centrifuge tubes. For extraction, ethyl acetate $(25 \mathrm{~mL})$ was added to each tube. The tube was stirred for 3 min on a vortex mixer, ultrasonic for $10 \mathrm{~min}$ and then centrifuged at $1372 \times \mathrm{g}$ for $5 \mathrm{~min}$, and then the liquid phase was transferred to a new tube. The remaining part was extracted again following the same extraction step, and the liquid phase was combined. The combined extract was passed through a funnel with about $10 \mathrm{~g}$ of anhydrous sodium sulfate to a pear shaped flask, and evaporated to dryness by vacuum rotary evaporator at $45^{\circ} \mathrm{C}$. The dry extract was diluted to $1.0 \mathrm{~mL}$ with isopropanol, and passed through a filter membrane (pore size, $0.22 \mu \mathrm{m})$.

For analysis of the earthworms, the samples were thawed for about $15 \mathrm{~min}$ at room temperature. Ethyl acetate $(25 \mathrm{~mL})$ was added to each tube. Next, the mixture was homogenized with Ultra-Turrax T18 homogenizer for $60 \mathrm{~s}$. The phases were vortexmixed for $3 \mathrm{~min}$, ultrasonic for $10 \mathrm{~min}$ and separated by centrifugation at $1372 \times g$ for $5 \mathrm{~min}$. The upper organic phase was passed through a funnel with about $10 \mathrm{~g}$ of anhydrous sodium sulfate to pear shaped flask. The same extraction step was repeated once with $25 \mathrm{~mL}$ of ethyl acetate, and the solvent extracts filtered 
through $5 \mathrm{~g}$ of anhydrous sodium sulfate for dehydration. The combined extract was evaporated to dryness at $45^{\circ} \mathrm{C}$. For cleanup (fat destruction), acetonitrile ( $5 \mathrm{~mL}$ ) was added to dissolve the extract, and then $3 \times 5 \mathrm{~mL}$ of $n$-hexane was added for liquid-liquid partition to extract most of lipid. The upper layer of $n$-hexane was discarded, and the layer of acetonitrile was evaporated to dryness by vacuum rotary evaporator at $45{ }^{\circ} \mathrm{C}$. The silica-SPE (500 mg) on a cartridge $(6 \mathrm{~mL})$ was used to clean up other interfering substances. The cartridge was preconditioned by rinsing with $5 \mathrm{~mL}$ of ethyl acetate followed by $5 \mathrm{~mL}$ of $n$-hexane and equilibrated with $10 \mathrm{~mL}$ of $1: 4$ ethyl acetate: $n$-hexane. The sample of dry extract was dissolved in $2 \mathrm{~mL}$ of $20 \%$ ethyl acetate in $n$-hexane, and then the solution passed through the SPE cartridge. The cartridge was eluted with additional $8 \mathrm{~mL}$ of $1: 4$ ethyl acetate: $n$-hexane. The elutes were combined with the loading elutes. The combined $10 \mathrm{~mL}$ of elutes were collected in a glass tube, evaporated to dryness under a stream of nitrogen, and diluted to $1.0 \mathrm{~mL}$ with isopropanol.

\subsubsection{Chemical analysis}

Chromatography in this study was performed using an Agilent 1200 Series HPLC (Agilent Technology) equipped with G1322A degasser, G1311A pump, G1329A ALS and G1314B VWD. AT-930 heater and cooler column attemperator (Titanjin Automatic Science Instrument Co. Ltd., China) was used to control column temperature. The signal was received and processed by Agilent chemstation software. The enantiomers of ethofumesate were separated on CDMPC-CSP (chiral stationary phase, provided by the Department of Applied Chemistry, China Agricultural University, Beijing). The CSP was prepared according to the procedure described in the literature (Zhou et al., 2003). CSP was packed into a $150 \times 4.6 \mathrm{~mm}$ (I.D.) stainless steel column. Chiral separation of the two enantiomers was performed using a mobile phase of $n$ hexane/isopropanol (96/4) with a flow rate of $0.5 \mathrm{~mL} / \mathrm{min}$ at a temperature of $20^{\circ} \mathrm{C}$. The injection volume was $20 \mu \mathrm{L}$, and the UV detection wavelength was $230 \mathrm{~nm}$. According to the result measured by CHIRALYSER-MP optical rotation detector, the first eluted enantiomer was (+)-ethofumesate and the second one was (-)ethofumesate. No enantiomerization had been observed for ethofumesate under these analytical conditions. Concentrations were determined by using peak area, assuming the same response factor for enantiomers originating from the same compound.

The average recoveries for both enantiomers at levels between 0.5 and $25 \mathrm{mg} / \mathrm{kg}$ ranged between $84.1 \%$ and $94.9 \%$ in earthworm tissue, and between $97.1 \%$ and $106.7 \%$ in soil with SD below $10 \%$ ( $n=3$ for each concentration). The limit of detection (LOD) for both enantiomers, defined as concentration produced a signal-to-noise ratio of 3, was $0.15 \mathrm{mg} / \mathrm{kg}$ both in earthworm tissue and soil.

\subsection{Data analysis}

\subsubsection{Earthworm bioaccumulation, elimination rates and biota-soil accumulation factors}

For the bioaccumulation experiment, a two-compartment (soil and worm) first-order kinetic model was used to describe the movement of contaminants into the worm according to the previous study (Klosterhaus et al., 2011). For this model, changes in the concentration of contaminants in the worm are described by the equation:

$d C_{w} / d t=k_{1} C_{s}-k_{2} C_{w}$

where $C_{w}$ is concentration of contaminant in the worm $\left(\mathrm{mg} / \mathrm{kg}_{\mathrm{wwt}}\right)$, $C_{s}$ is concentration of contaminant in the soil $\left(\mathrm{mg} / \mathrm{kg}_{\mathrm{dwt}}\right), k_{1}$ is uptake rate constant $\left(\mathrm{kg}_{\mathrm{dwt}} / \mathrm{kg}_{\mathrm{wwt}}\right.$ per day), and $k_{2}$ is the elimination constant estimated for the bioaccumulation phase $\left(\mathrm{d}^{-1}\right) ; t$ is time (d). With initial conditions of $t=0, C_{w}=0$, and $C_{s}=$ constant, this equation has the simple solution of

$C_{w}=C_{s}\left(k_{1} / k_{2}\right)\left(1-e^{-k_{2} t}\right)$

Normally $k_{1}$ and $k_{2}$ can be estimated by fitting the first-order model to measured contaminant residues using an iterative, nonlinear, least squares curve-fitting technique. However, because the concentration in the worm did not reach steady-state, resulting in the uptake data did not fit the nonlinear model, the uptake rate constant was estimated from linear regression of the concentration in the worm on days $0.5,1,3,5,10$ and 14 of uptake (when elimination processes were assumed to be negligible) normalized to the soil concentration on the same day, versus time (SPSS 16.0). This technique has been recommended as an alternative to the nonlinear curve fitting method (Landrum et al., 1992) and used in other studies (Boese et al., 1997).

For the elimination experiment, earthworm elimination data were fitted to a one-compartment, first-order kinetic elimination model (Eq. (3)), and the elimination half-life $\left(T_{1 / 2}\right)$ was determined by Eq. (4):

$C_{w}(t)=C_{w}(0) e^{-k_{3} t}$

$T_{1 / 2}=0.693 / k_{3}$

where $C_{w}(t)$ is the concentration of the earthworm $\left(\mathrm{mg} / \mathrm{kg}_{\mathrm{wwt}}\right)$ at time $t(\mathrm{~d})$ during the elimination phase, $C_{w}(0)$ is the concentration $\left(\mathrm{mg} / \mathrm{kg}_{\mathrm{wwt}}\right)$ of the earthworm at the start of the elimination phase, and $k_{3}$ is the elimination rate constant $\left(\mathrm{d}^{-1}\right)$.

The relative accumulation of ethofumesate enantiomers was expressed as biota to soil accumulation factor (BSAF, $\mathrm{kg}_{\mathrm{wwt}} / \mathrm{kg}_{\mathrm{dwt}}$ ).

$\operatorname{BSAF}\left(\mathrm{kg}_{\mathrm{dwt}} / \mathrm{kg}_{\mathrm{wwt}}\right)=C_{w} / C_{s}$

where $C_{w}$ and $C_{s}$ are concentrations of ethofumesate enantiomers in earthworm and soil, respectively.

\subsubsection{Enantioselecitvity analysis}

The data of the residual concentrations of the two enantiomers were used for estimating the enantiomer fraction (EF) values during these experiments. EF was used to measure the enantioselectivity during the experiment, and the EF values defined range from 0 to 1 , with $\mathrm{EF}=0.5$ representing the racemic mixture. $\mathrm{EF}$ was expressed as follows:

$\mathrm{EF}=$ area of $(+) /[(-)+(+)]$

where $(+)$ is the first eluted chromatograph peak of (+)-enantiomer and $(-)$ is the second eluted peak of $(-)$-enantiomer.

Data of bioaccumulation and elimination experiment presented corresponds to means \pm standard deviations of three independent experiment $(N=3)$. Statistical analysis for the enantioselectivity of ethofumesate enantiomers was performed using SPSS 16.0. A one sample $t$-test was used to compare the means of the EF values in earthworm and soil samples with $\mathrm{EF}=0.5$. The concentrations and BSAFs of the two enantiomers of ethofumesate were analyzed using one way analysis of variance (one-way ANOVA), and pair wise multiple comparison procedure ( $S-N-K$ test) was used to compare results at $p<0.05$. In acute toxicity assay, the 50\% lethal concentration $\left(\mathrm{LC}_{50}\right)$ and associated $95 \%$ confidence intervals were estimated from the survival data using a probit equation.

\section{Results and discussion}

\subsection{Acute toxicity assay}

The acute toxicity was measured by paper contact test for individual enantiomers and racemate using E. fetida as the test 
organisms. The mortality increased with increasing concentrations of individual enantiomer and racemate of ethofumesate, and the $\mathrm{LC}_{50}$ values for individual enantiomer and rac-ethofumesate were calculated and shown in Table 1 . Based on the $\mathrm{LC}_{50}$ values of these compounds, the order of toxicity potency to E. fetida at $48 \mathrm{~h}$ was $(+)$-ethofumesate $>$ rac-ethofumesate $>(-)$-ethofumesate. The calculated $\mathrm{LC}_{50}$ of (-)-enantiomer was about 1.8 times of that for (+)enantiomer after $48 \mathrm{~h}$ of exposure. These results indicated that the acute toxicity of ethofumesate enantiomers to earthworm was slightly enantioselective. It is common for the acute toxicity effects of chiral pesticides on earthworm to be associated primarily with only one of the enantiomers. Our previous studies (Diao et al., 2011; Xu et al., 2009) have showed (+)-(1R-cis-aS)-alpha-cypermethrin was 30 times more toxic than the (-)-enantiomer, and the $R$-(-)-benalaxy exhibited acute toxicity was about 2 times of that for the $S-(+)$-enantiomer. So far, researchers always focus on the efficacy of chiral pesticides while neglecting the passive biological effects associated with specific enantiomers that have a long persistence in the environment after application. In the previous study (Klosterhaus et al., 2011), a preferential degradation of (-)ethofumesate in one soil was observed, resulting in residues enriched with (+)-ethofumesate. In other words, the abundance and high toxicity of (+)-ethofumesate may have harmful effects on the environment. Therefore, the present data available on the toxicity of the racemic mixtures of these chiral pesticides are not reliable, and the study of enantioselective toxicity of chiral pesticides has been very important for environmental safety issues (Lin et al., 2008; Cai et al., 2008).

\subsection{Dissipation of ethofumesate enantiomers in soil}

The initial concentrations of enantiomers were both $20 \mathrm{mg} / \mathrm{kg}_{\mathrm{dwt}}$ at dose of $40 \mathrm{mg} / \mathrm{kg}_{\mathrm{dwt}}$. In general, the residues of both enantiomers of ethofumesate decreased with time elapsed in soil. The data on dissipation of ethofumesate in soil are presented in Fig. S2. As illustrated in Fig. S2, the data for (+)- and (-)-ethofumesate showed a slowly decrease of the concentration to $68.1 \%$ and $64.7 \%$, respectively, after $40 \mathrm{~d}$ of exposure. The EF values of ethofumesate enantiomers in soil were also calculated, and these values were found to be constant with time (Fig. 2). A t-test between the $\mathrm{EF}$ values in the soil and $\mathrm{EF}=0.5$ yielded a $p$ value of 0.152 , indicating that the dissipation of ethofumesate enantiomers in the soil was not enantioselective.

\subsection{Bioaccumulation of ethofumesate enantiomers in earthworm}

The accumulation of two enantiomers of ethofumesate in earthworm during exposure was shown in Fig. 3. As illustrated in Fig. 3, a peak in the accumulation curve was noted for the two enantiomers. During the initial $0.5 \mathrm{~d}$ of exposure, the amount of (+)- and (-)-ethofumesate detected in earthworm were both $8.8 \mathrm{mg} / \mathrm{kg}_{\text {wwt }}$. After further exposure, the concentrations of (+)- and (-)-ethofumesate reached a maximum of 29.3 and $28.1 \mathrm{mg} / \mathrm{kg}_{\mathrm{wwt}}$ at day 10 , respectively, and then disappeared to 17.8 and $16.8 \mathrm{mg} / \mathrm{kg}_{\mathrm{wwt}}$

Table 1

Calculated $\mathrm{LC}_{50}$ values of enantiomers from ethofumesate for earthworm E. fetida.

\begin{tabular}{lllll}
\hline Chemicals & $\begin{array}{l}48-\mathrm{h}-\mathrm{LC}_{50} \\
\left(\mu \mathrm{g} / \mathrm{cm}^{2}\right)\end{array}$ & $\begin{array}{l}\text { 95\% Confidence } \\
\text { intervals }\end{array}$ & $R^{\mathrm{a}}$ & $p^{\mathrm{b}}$ \\
\hline (+)-Ethofumesate & 4.51 & $2.22-7.08$ & 0.992 & $<0.001$ \\
Racemate & 5.93 & $3.87-8.64$ & 0.978 & 0.001 \\
(-)-Ethofuesate & 7.98 & $4.02-11.88$ & 0.934 & 0.006 \\
\hline
\end{tabular}

\footnotetext{
a Represents the correlation coefficient.
}

b Represents the probability. A p-value smaller than 0.05 indicates that the correlation of linear equation is significant.

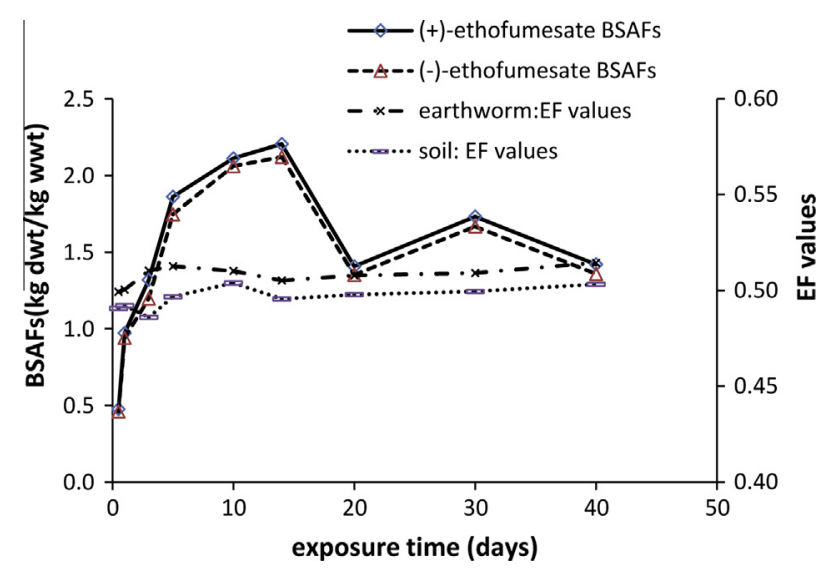

Fig. 2. BSAFs for two enantiomers of ethofumesate and EF values during exposure time.

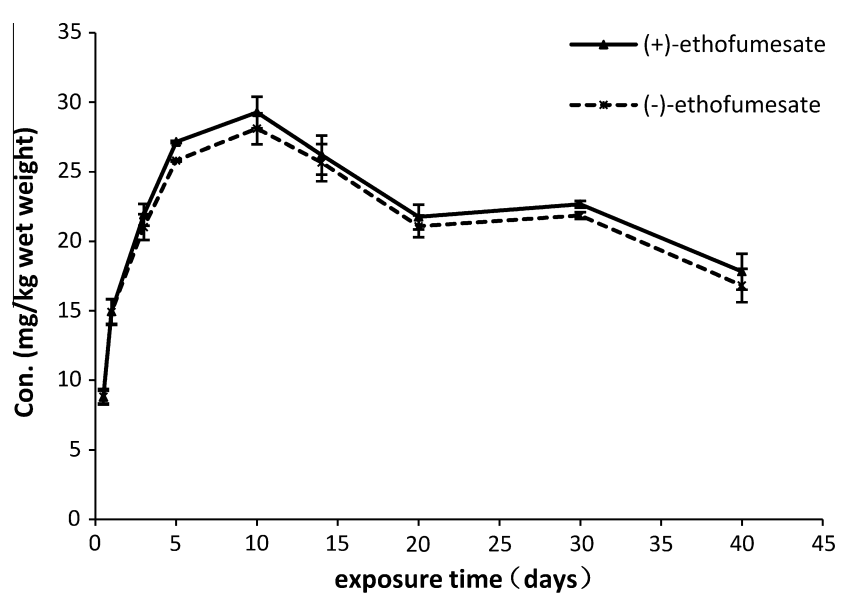

Fig. 3. Concentrations of two enantiomers of ethofumesate in earthworm samples during bioaccumulation experiment (bars are standard error).

at day 40 , respectively. There are several possible explanations for the peak-shaped accumulation curve. One possible is induction of active excretion by the worm (Reinecke and Nash, 1984). The second possible is an increase of sorption in soil with exposure time increased, which caused bioavailability to decline (Ma et al., 1995). A gradual reduction in the concentration of ethofumesate enantiomers in the soil during the experiment is the third possible explanation for this observation. In addition, growth may result in a dilution and therefore in a decrease of the concentration of the compound in the worm (Belfroid et al., 1995). This model of peak shaped bioaccumulation curves in earthworm was similar to the models found by our previous studies (Diao et al., 2011; Xu et al., 2011). A peak in the accumulation curve was also noted for alpha-cypermethrin and benalaxyl in earthworm. However, the bioaccumulation of metalaxyl was different from the above pesticides. It can be absorbed by earthworm quickly and reached the steady state within only one day (Xu et al., 2009).

Because the accumulation of ethofumesate in earthworm did not reach a steady state, we performed a linear regression of the concentration in the worm on days $0.5,1,3,5,10$ and 14 normalized to the soil concentration on the same day, versus time. The uptake rate constants for (+)- and (-)-ethofumesate from spiked soil to earthworm was 0.114 and $0.112 \mathrm{~kg}_{\mathrm{dwt}} / \mathrm{kg}_{\text {wwt }}$ per day, respectively (Table 2 ). In order to investigate whether the enantioselectivity occurred in the bioaccumulation process, the EF values in earthworm were also calculated, and shown in Fig. 2 . The values were 0.5 at the beginning, and have remained largely unchanged. 
Table 2

Uptake and elimination rate constants (with 95\% confidence intervals) for the accumulation of ethofumesate enantiomers in earthworm with an initial racethofumesate concentration of $40 \mathrm{mg} / \mathrm{kg}_{\mathrm{dwt}}$ in soil.

\begin{tabular}{lllllll}
\hline Compound & $\begin{array}{l}k_{1}\left(\mathrm{~kg}_{\mathrm{dwt}} /\right. \\
\left.\mathrm{kg}_{\text {wwt }} \text { per day }\right)\end{array}$ & $R^{\mathrm{a}}$ & $p^{\mathrm{b}}$ & $\begin{array}{l}k_{3} \\
\left(\mathrm{~d}^{-1}\right)\end{array}$ & $R^{\mathrm{c}}$ & $p^{\mathrm{d}}$ \\
\hline (+)-Ethofumesate & 0.114 & 0.895 & 0.016 & 0.386 & 0.951 & 0.004 \\
(-)-Ethofumesate & 0.112 & 0.906 & 0.013 & 0.384 & 0.941 & 0.005
\end{tabular}

a Represents the correlation coefficient of uptake equation.

b Represents the probability. A $p$-value smaller than 0.05 indicates that the correlation of linear equation is significant.

c Represents the correlation coefficient of elimination equation.

d Represents the probability. A p-value smaller than 0.05 indicates that the correlation of exponential equation is significant.

The ethofumesate bioaccumulation was also assessed through calculation of BSAFs values (Fig. 2). On the 14th day, concentrations of two enantiomers of ethofumesate reached maximum values in earthworm and in the following days, they showed the same tendency which could be described as a "decrease-increase-decrease" process. This phenomenon was consistent with the previous study (Landrum et al., 1992), in which bioavailability of chemicals generally decreases with increasing sediment-chemical contact time. Based on the one-way ANOVA analysis, no significant difference was observed between the BSAFs values of two enantiomers. These results indicated that the bioaccumulation of ethofumesate enantiomers in earthworm was nonenantioselective.

\subsection{Log BSAFs and Log $K_{\text {ow }}$ relationship}

In Table 3, the BSAFs values of some pesticides studied by us were listed, and further investigated by plotting with Log $K_{\text {ow }}$ values (Fig. 4). As illustrated in Fig. 4, a linear relationship between Log BSAFs and Log $K_{\text {ow }}$ for metalaxyl, ethofumesate, $\alpha-\mathrm{HCH}$ and hexaconazole was observed when alpha-cypermethrin is removed from the data set. This chemical can be considered an outlier as it may be metabolized quickly in earthworm. The other possible explanation is the bioavailability for high $K_{\mathrm{ow}}$ chemicals generally decreases with increasing hydrophobicity because of stronger associations with sediment/soil organic matter and lower solubility in water and digestive fluids (Klosterhaus et al., 2011; Weston and Mayer, 1998). Except alpha-cypermethrin, the BSAFs values for other pesticides increased with increasing $K_{\text {ow }}$, indicating that $K_{\text {ow }}$ is an appropriate descriptor for the affinity of these four chemicals to worm tissues. However, nonlinear relationships between BSAFs and $K_{\text {ow }}$ are often reported and several explanations have been suggested, including a reduction in uptake because of steric hindrance (Opperhuizen et al., 1985) or reduced bioavailability (Gobas et al., 1989; Verhaar et al, 1999).

\subsection{Elimination of ethofumesate enantiomers in earthworm}

After $14 \mathrm{~d}$ of exposure, some earthworms were transferred to the uncontaminated soil for the elimination test. The elimination

Table 3

Octanol-water partition coefficients $\left(K_{\mathrm{ow}}\right)$ and BSAFs values of chemicals for earthworm (E. fetida).

\begin{tabular}{lllc}
\hline References & Chemical & $\begin{array}{l}\text { Log } \\
K_{\mathrm{ow}}\end{array}$ & $\begin{array}{c}\text { Log BSAFs } \\
\left(\mathrm{kg}_{\mathrm{dwt}} / \mathrm{kg}_{\mathrm{wwt}}\right)\end{array}$ \\
\hline Xu et al. (2011) & Metalaxyl & 1.8 & -0.77 \\
/ & Ethofumesate & 2.7 & 0.36 \\
Zhou et al. (2012) & $\alpha$-HCH & 3.5 & 0.44 \\
Xu et al. (2013) & Hexaconazole & 3.9 & 0.61 \\
$\quad$ unpublished work & Alpha-cypermethrin & 6.9 & -1.76 \\
\hline Diao et al. (2011) & & & \\
\hline
\end{tabular}

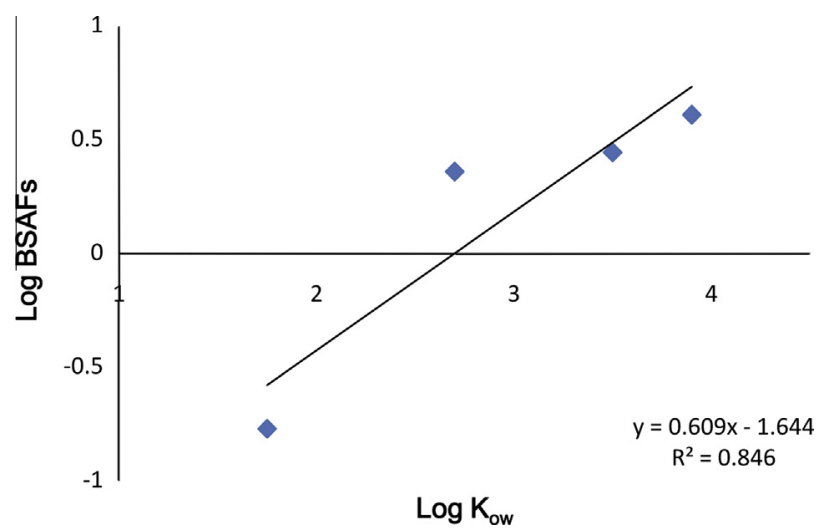

Fig. 4. Relationship between Log BSAFs and Log $K_{\text {ow }}$ for the accumulation of pesticides in earthworm (E. fetida). Log $K_{\text {ow }}$ values are from Table 3.

of ethofumesate enantiomers residues from the earthworms was observed for $4 \mathrm{~d}$. As illustrated in Fig. S3, the concentrations of the two enantiomers both declined over time. The experimental data fitted well to the first-order decay model (Eq. (3)), with parameter $\left(k_{3}\right)$ given in Table 2 . The two enantiomers had the same elimination rate constant $\left(k_{3} \approx 0.38 \mathrm{~d}^{-1}\right)$ with the same half-life $\left(T_{1 / 2}\right)$ of $1.8 \mathrm{~d}$, indicating that the elimination of ethofumesate enantiomers in earthworm was also nonenantioselective. Comparison with the results from other studies (Diao et al., 2011; Xu et al., 2011; Zhou et al., 2012), we found the elimination of metalaxyl, $\alpha$ $\mathrm{HCH}$ and alpha-cypermethrin in earthworm were both fast, and the half life of these chemicals were less than $2 \mathrm{~d}$. However, the elimination of hexaconazole in earthworm was slower than that of the above pesticides with a long half life of $7.3 \mathrm{~d}$ ( $\mathrm{Xu}$ et al., 2013, Supplementary data). Based on these results, it can be concluded the elimination of these pesticides in earthworm was independent of $K_{\text {ow }}$, and it may be affected by feeding (Jager et al. 2005).

\section{Conclusion}

To our knowledge, this study provides the first results of the acute toxicity and kinetics of bioaccumulation and elimination of ethofumesate enantiomers in earthworms. Filter paper contact acute toxicity test showed that (+)-ethofumesate was 1.8 times more toxic for earthworm than (-)-ethofumesate. Methods to determine the concentrations of two enantiomers of ethofumesate in soil and earthworm were developed by HPLC based on CDMPC. The bioaccumulation data indicate that ethofumesate can be remobilized from soil and absorbed by earthworm, then this chemical may be transferred to the higher-trophic-level species. The elimination data indicate that the concentrations of ethofumesate in earthworm decreased over time because of the metabolism or excretion. Chemical hydrophobicity $\left(K_{\text {ow }}\right)$ was a good predictor of bioavailability for metalaxyl, ethofumesate, $\alpha-\mathrm{HCH}$ and hexaconazole, but the elimination of these chemicals in earthworm did not rely on $K_{\text {ow }}$.

\section{Acknowledgment}

This work was supported by fund from the National Natural Science Foundation of China (Contract Grant number: 41301569).

\section{Appendix A. Supplementary material}

Supplementary data associated with this article can be found, in the online version, at http://dx.doi.org/10.1016/j.chemosphere. 2014.03.120. 


\section{Reference}

Belfroid, A.C., Scinen, W., van Gestel, K.C.A.M., Hermens, J.L.M., van Leeuwen, K.J., 1995. Modelling the accumulation of hydrophobic organic chemicals in earthworms. Environ. Sci. Pollut. Res. 2, 5-15.

Boese, B.L., Lee, H., Echols, S., 1997. Evaluation of a first-order model for the prediction of the bioaccumulation of PCBs and DDT from sediment into the marine deposit-feeding clam Macoma nasuta. Environ. Toxicol. Chem. 16, 1545-1553.

Cai, X.Y., Liu, W.P., Sheng, G.Y., 2008. Enantioselective degradation and ecotoxicity of the chiral herbicide diclofop in three freshwater alga cultures. J. Agric. Food Chem. 56, 2139-2146.

Diao, J.L., Xu, P., Wang, P., Lu, Y.L., Lu, D.H., Zhou, Z.Q. 2010. Environmental behavior of the chiral aryloxyphenoxypropionate herbicide diclofop-methyl and diclofop: enantiomerization and enantioselective degradation in soil. Environ. Sci. Technol. 44, 2042-2047.

Diao, J.L., Xu, P., Liu, D.H., Lu, Y.L., Zhou, Z.Q., 2011. Enantiomer-specific toxicity and bioaccumulation of alpha-cypermethrin to earthworm Eisenia fetida. J. Hazard. Mater. 192, 1072-1078.

Garrison, A.W., Schmitt, P., Martens, D., Kettrup, A., 1996. Enantiomeric selectivity in the environmental degradation of dichlorprop as determined by highperformance capillary electrophoresis. Environ. Sci. Technol. 30, 2449-2455.

Gobas, F.A.P.C., Clark, K.E., Shiu, W.Y., Mackay, D., 1989. Bioconcentration of polybrominated benzenes and biphenyls and related superhydrophobic chemicals in fish: role of bioavailability and elimination into the feces. Environ. Toxicol. Chem. 8, 231-245.

Jager, T., Fleuren, R.H.L., Roelofs, W., De Groot, A.C., 2003a. Feeding activity of the earthworm Eisenia andrei in artificial soil. Soil Biol. Biochem. 35, 313-322.

Jager, T., Fleuren, R.H.L.J., Hogendoorn, E.A., De Korte, G., 2003b. Elucidating the routes of exposure for organic chemicals in the earthworm, Eisenia andrei (Oligochaeta). Environ. Sci. Technol. 37, 3399-3404.

Jager, T., Van Der Wal, L., Fleuren, R.H., Barendregt, A., Hermens, J.L., 2005. Bioaccumulation of organic chemicals in contaminated soils: evaluation of bioassays with earthworms. Environ. Sci. Technol. 39, 293-298.

Katayama, A., Bhula, R., Burns, G.R., Carazo, E., Felsot, A., Hamilton, D., Harris, C. Kim, Y., Kleter, G., Koedel, W., Linders, J., Peijnenburg, J.G.M.W., Sabljic, A., Stephenson, R.G., Racke, D.K., Rubin, B., Tanaka, K., Unsworth, J., Wauchope, R.D. 2010. Bioavailability of xenobiotics in the soil environment. In: Whitacre, D.M. (Ed.), Reviews of Environmental Contamination and Toxicology. Springer, New York, pp. 1-86.

Kawahigashi, H., Hirose, S., Hayashi, E., Ohkaw, H., Ohkawa, Y., 2002. Phytotoxicity and metabolism of ethofumesatein transgenic rice plants expressing the human CYP2B6 gene. Pestic. Biochem. Phys. 74, 139-147.

Kinney, C.A., Furlong, E.T., Kolpin, D.W., Burkhardt, M.R., Zaugg, S.D., Werner, S.L., Bossio, J.P., Benotti, M.J., 2008. Bioaccumulation of pharmaceuticals and other anthropogenicwaste indicators in earthworms from agricultural soil amendedwith biosolid or swine manure. Environ. Sci. Technol. 42, 1863-1870.

Kizilkaya, R., 2004. Cu and Zn accumulation in earthworm Lumbricus terrestris L. in sewage sludge amended soil and fractions of $\mathrm{Cu}$ and $\mathrm{Zn}$ in casts and surrounding soil. Ecol. Eng. 22, 141-151.

Klosterhaus, S.L., Dreis, E., Baker, J.E., 2011. Bioaccumulation kinetics of polybrominated diphenyl ethers from estuarine sediments to the marine polychaete, Nereisvirens. Environ. Toxicol. Chem. 30, 1204-1212.

Kucharski, M., Sadowski, J., 2009. Degradation of ethofumesate in soil under laboratory conditions. Pol. J. Environ. Stud. 2, 243-247.

Landrum, P.F., Lee, H., Lydy, M.J., 1992a. Toxicokinetics in aquatic systems: model comparisons and use in hazard assessment. Environ. Toxicol. Chem. 11, 17091725.

Landrum, P.F., Eadie, B.J., Faust, W.R., 1992b. Variation in the bioavailability of polycyclic aromatic hydrocarbons to the amphipod Diporeia (spp.) with sediment aging. Environ. Toxicol. Chem. 11, 1197-1208.

Lavelle, P., Bignell, D., Lepage, M., Wolters, V., Roger, P., Ineson, P., Heal, O.W., Dhillion, S., 1997. Soil function in a changing world: the role of invertebrate ecosystem engineers. Eur. J. Soil Biol. 33, 159-193.

Lin, K.D., Liu, W.P., Li, L., Gan, J., 2008. Single and joint acute toxicity of isocarbophos enantiomers to Daphnia magna. J. Agric. Food Chem. 56, 4273-4277.

Liu, T.T., Wang, P., Lu, Y.L., Diao, J.L., Zhou, Z.Q., 2012. Enantioselective bioaccumulation of soil-associated fipronil enantiomers in Tubifex tubifex. J. Hazard. Mater. 15, 50-56.
Ma, W.C., Immerzeel, J., Bodt, J., 1995. Earthworm and food interactions on bioaccumulation and disappearance in soil of polycyclic aromatic hydrouscarbons: studies on phenanthrene and fluoranthene. Ecotoxicol. Environ. Saf. 32, 226-232.

Matthews, G.A., 2006. Pesticides: Health, Safety and The Environment. Blackwell Publishing, Oxford, UK.

OECD, 1984. Guidelines for Testing of Chemicals, Earthworm. Acute Toxicity Tests; Organization for Economic Cooperation and Development, Paris. 207.

Opperhuizen, A., Van der Velde, E.W., Gobas, F.A.P.C., Liem, D.A.K., Van der Steen, J.M.D., Hutzinger, O., 1985. Relationship between bioconcentration in fish and steric factors of hydrophobic chemicals. Chemosphere 14, 1871-1896.

Overmyer, J.P., Rouse, D.R., Avants, J.K., Garrison, A.W., DeLorenzo, M.E., Chung, K.W., Key, P.B., Wilson, W.A., Black, M.C., 2007. Toxicity of fipronil and its enantiomers to marine and freshwater non-targets. J. Environ. Sci. Health B 42, 471-480.

Reinecke, A.J., Nash, R.G., 1984. Toxicity of 2,3,7,8-TCDD and short-term bioaccumulation by earthworms (Oligochaeta). Soil Biol. Biochem. 16, 45-49.

Sáenz de CabezónIrigaray, F.J., Montoya Carvajal, L.D., Moreno Grijalba, F., 2009. Pesticides and longevity. In: Bentely, J.V., Keller, M.A. (Eds.), Handbook on Longevity: Genetics, Diet and Disease. Nova Science Publisher, Hauppauge NY (Chap. 7)

Shan, J., Wang, T., Li, C.L., Klumpp, E., Ji, R., 2010. Bioaccumulation and boundresidue formation of a branched 4-nonylphenol isomer in the geophagous earthworm metaphire guillelmi in a rice paddy soil. Environ. Sci. Technol. 44, 4558-4563.

Shang, H.T., Wang, P., Wang, T.H., Wang, Y.W., Zhang, H.D., Fu, J.J., Ren, D.W., Chen, W.H., Zhang, Q.H., Jiang, G.B., 2013. Bioaccumulation of PCDD/Fs, PCBs and PBDEs by earthworms in field soils of an E-waste dismantling area in China. Environ. Pollut. 54, 50-58.

Snyder, E.H., O'Connor, G.A., McAvoy, D.C., 2011. Toxicity and bioaccumulation of biosolids-borne triclocarban (TCC) in terrestrial organisms. Chemosphere 82, 460-467.

Sun, M.J., Liu, D.H., Dang, Z.H., Li, R.H., Zhou, Z.Q., Wang, P., 2012. Enantioselective behavior of malathion enantiomers in toxicity to beneficial organisms and their dissipation in vegetables and crops. J. Hazard. Mater. 237, 140-146.

US Environmental Protection Agency, 2005. Reregistration eligibility decision for ethofumesate. Case No. 2265.

Verhaar, H.J.M., De Jongh, J., Hermens, J.L.M., 1999. Modeling the bioconcentration of organic compounds by fish: a novel approach. Environ. Sci. Technol. 33 4069-4072.

Wang, P., Jiang, S.R., Qiu, J., Wang, Q.X., Wang, P., Zhou, Z.Q., 2005. Stereoselective degradation of ethofumesate in turfgrass and soil. Pestic. Biochem. Phys. 82, 197-204.

Weston, D.P., Mayer, L.M., 1998. Comparison of in vitro digestive fluid extraction and traditional in vivo approaches as measures of polycyclicaromatic hydrocarbon bioavailability from sediments. Environ. Toxicol. Chem. 17, 830840.

Wilson, R.G., 1999. Response of nine sugar beet (Beta vulgaris) cultivars to postemergence herbicide applications. Weed Technol. 13, 25-29.

Xu, P., Liu, D.H., Diao, J.L., Lu, D.H., Zhou, Z.Q., 2009. Enantioselective acute toxicity and bioaccumulation of benalaxyl in earthworm (Eisenia fedtia). J. Agric. Food Chem. 57, 8545-8549.

Xu, P., Diao, J.L., Liu, D.H., Zhou, Z.Q., 2011. Enantioselective bioaccumulation and toxic effects of metalaxyl in earthworm Eisenia fetida. Chemosphere 83, 10741079.

Xu, X.Y., Diao, J.L., Wang, X.R., Dang, Z.H., Zhang, P., Li, Y.B., Zhou, Z.Q., 2012. Enantioselective metabolism and cytotoxicity of the chiral herbicide ethofumesate in rat and chicken hepatocytes. Pestic. Biochem. Phys. 103, 6267.

Xu, P., Li, J.Z., Wang, H.L., 2013. Toxicity and bioaccumulation of soil-associated triazole fungicide hexaconazole enantiomers in earthworm. Unpublished work.

Zhou, Z.Q., Wang, P., Jiang, S.R., 2003. The preparation of polysac-charide-based chiral stationary phase and the direct separation of five chiral pesticides and related intermediates. J. Liq. Chromatogr. Relat. Technol. 26, 2873-2880.

Zhou, G.X., Liu, D.H., Ma, R.X., Li, J.D., Sun, M.J., Zhou, Z.Q., Wang, P., 2012. Enantioselective kinetics of $\alpha$-hexachlorocyclohexane in earthworm (Eisenia fedtia) and forest soil. Chirality 24, 615-620. 